\title{
Correction to: Model-based strategic planning for strengthening mushroom entrepreneurship: insights from a sub-Himalayan Region of West Bengal, India
}

\author{
Pritha Datta $(\mathbb{D} \cdot$ Soumik Das $\mathbb{B}$
}

Published online: 22 February 2020

(C) Springer Nature B.V. 2020

\section{Correction to: GeoJournal}

https://doi.org/10.1007/s10708-019-10063-9

In the original publication, there are few mistakes in Figs. 1, 2 and Table 5. The corrected version is given as follows (Figs. 1, 2 and Table 5).

The original article can be found online at https:// doi.org/10.1007/s10708-019-10063-9.

P. Datta $(\bowtie)$

Department of Geography, Aryabhatta School of Earth Sciences, Assam University, Diphu Campus, Assam, India e-mail: dattapritha3@gmail.com

S. Das

Department of Geography, School of Human and Environmental Sciences, North-Eastern Hill University, Shillong, India

Present Address:

S. Das

Department of Humanities and Social Sciences, Indian Institute of Technology Kharagpur, Kharagpur, India 

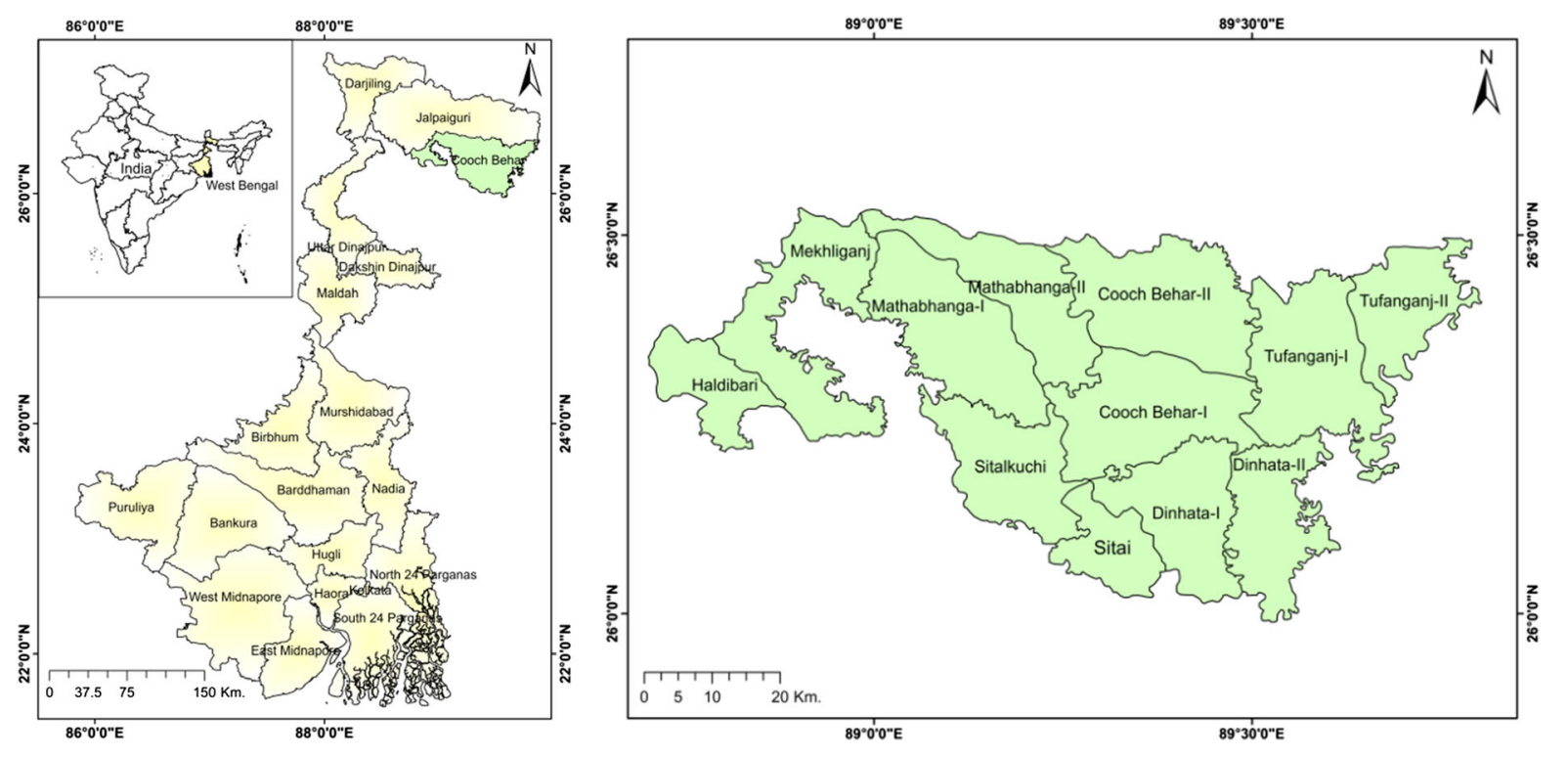

Fig. 1 Geographical location of the study area

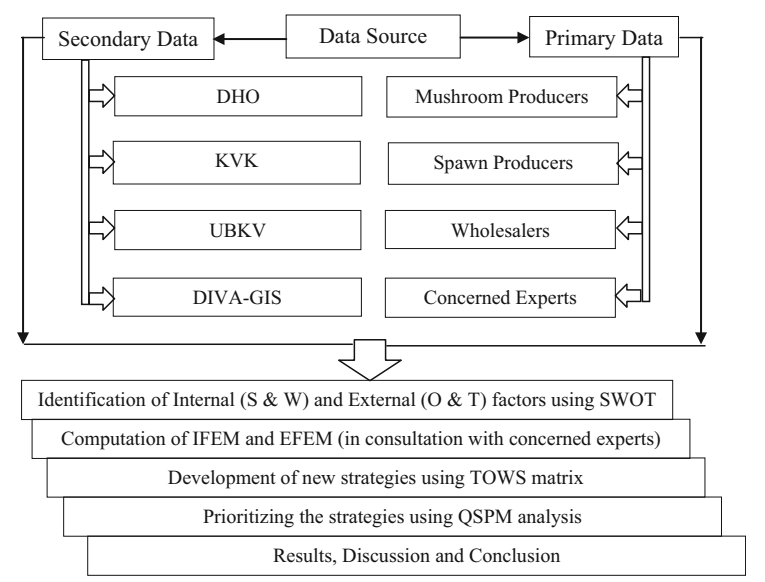

Fig. 2 Flow chart of the present study 
Table 5 Initial average capital investment and profit from oyster mushroom production (500 cylinders)

\begin{tabular}{llll}
\hline Particulars & Amount in unit & Market price/unit in Rs. & Cost in Rs. \\
\hline Construction of mushroom house & 1 no. & - & 10,000 \\
Paddy straw & 1500 bundles & 1.50 & 2250 \\
Spawn & 500 packets & 12 & 6000 \\
Labour & 8 persons & 220 & 1760 \\
Lime & $57 \mathrm{~kg}$ & 12 & 684 \\
Pesticide and fungicide & 11 & 500 & 500 \\
Polythene bags & $5 \mathrm{~kg}$ & 150 & 750 \\
Motor $(1 \mathrm{HP})$ & $1 \mathrm{no}$. & 2500 & 2500 \\
Spray machine $(81$ capacity) & $1 \mathrm{no.}$ & 1500 & 1500 \\
Total cost & - & - & 25,944 \\
\hline Particulars & Amount in unit & Market price/unit in Rs. & Revenue in Rs. \\
\hline Total mushroom production & $875 \mathrm{~kg}$ & $55 / \mathrm{kg}$ & 48,125 \\
Profit $=$ (Revenue - Cost) $=22,181$ & & &
\end{tabular}

Source: Author's calculation

Publisher's Note Springer Nature remains neutral with regard to jurisdictional claims in published maps and institutional affiliations. 